\title{
A Proposed New Laboratory Protocol for Dispersant Effectiveness Testing Adapted for Subsea Dispersant Injection
}

\author{
Per Johan Brandvik ${ }^{*}$ (D, Per S. Daling1, Dorien Dunnebier1, Panagiotis E. Makatounis², \\ Frode Leirvik ${ }^{1}$, Daniel F. Krause ${ }^{1}$ \\ ${ }^{1}$ SINTEF Ocean, Marine Environmental Technology, Trondheim, Norway \\ ${ }^{2}$ National Technical University of Athens, Athens, Greece \\ Email: * per.brandvik@sintef.no
}

How to cite this paper: Brandvik, P.J., Daling, P.S., Dunnebier, D., Makatounis, P.E., Leirvik, F. and Krause, D.F. (2019) A Proposed New Laboratory Protocol for Dispersant Effectiveness Testing Adapted for Subsea Dispersant Injection. Journal of Environmental Protection, 10, 694-709. https://doi.org/10.4236/jep.2019.105041

Received: April 5, 2019

Accepted: May 24, 2019

Published: May 27, 2019

Copyright $\odot 2019$ by author(s) and Scientific Research Publishing Inc. This work is licensed under the Creative Commons Attribution International License (CC BY 4.0).

http://creativecommons.org/licenses/by/4.0/

\begin{abstract}
The main objective of this study is to develop a new protocol for bench-scale dispersant effectiveness testing adapted for subsea dispersants injection (SSDI). The new approach includes turbulence conditions, dispersant injection techniques and quantification of effectiveness, more representative for a SSDI operation. Results from the new system are compared to dispersant effectiveness measured with established laboratory methods, used for screening dispersants for surface application. The most significant result is that the dispersant ranking obtained with the new test relevant for subsea releases was very different compared to the ranking obtained by screening methods used for surface application of dispersants. This strongly indicates that existing standard methods for dispersant effectiveness testing designed for simulating conditions relevant for surface application of dispersants, are less relevant for SSDI effectiveness testing and justify the need for a more relevant method. Such a Dispersant Injection Effectiveness Test (DIET) is suggested and documented in this study.
\end{abstract}

\section{Keywords}

Subsea, Oil Spill, Laboratory, Effectiveness Testing, Dispersants

\section{Introduction}

Both for oil spill contingency planning and in operational situations where dispersants are used, selecting the most effective product is important. The effectiveness of available dispersants products varies as a function of product and oil properties, dosage, water salinity, oil weathering degree and application effec- 
tiveness. In addition, other properties like toxicity, biodegradability and viscosity could influence product selection. Oil fields operators or refinery owners usually screen different products on actual oil types to document their selection of dispersant. Which products to stockpile could be a compromise of dispersant effectiveness on a selection of different oil types and environmental conditions (temperature and salinity).

Multiple laboratory methods have been developed, over the last four decades, to measure dispersant effectiveness. These methods give relative effectiveness and are mainly used to compare products. The test methods usually consist of a container holding a water volume, an application system for oil and dispersant and a system for simulating turbulence at sea. The effectiveness is usually described by the amount of oil removed from the surface, often by quantifying the oil content in the water in the experimental system. Different standard test methods have been developed over the years, MNS (Canada), WSL (UK), IFP (France), EXDET (USA) and Swirling/Baffled flask (USA) [1]-[7]. Many of these methods are included in national protocols for dispersant approval or used indispersant screening studies (product/oil types) and for dispersant research and development. The mechanisms for simulating surface turbulence are very different in these methods (rotation, shacking, air stream or a moving piston) and represent a wide range of turbulence levels. It is important to remember that these laboratory methods only give a relative effectiveness and does not necessarily reflect the effectiveness obtained when the products are applied in a real situation.

The turbulence regime in a few of these laboratory test systems have been characterised and related to sea turbulence or sea states, for example, the Swirling-and Baffled flask test [8] [9]. Studies have tried to correlate results from different laboratory methods including correlating them towards effectiveness from basin studies [9]-[14]. Since the energy levels, dispersant application methods (premixed or applied on oil) and sampling regimes (static/dynamic) are different, it is often difficult to obtain high correlations between the effectiveness measured with the different laboratory methods. Limited data exists from field testing of dispersant effectiveness that can be correlated against laboratory studies, however, work have been performed in UK [15] [16] and in Norway [17] [18] [19].

When dispersants are sprayed on surface oil slicks, changes in oil properties due to weathering (e.g. increased viscosity due evaporation and emulsification) influence the dispersant effectiveness [20]. This usually implies that dispersant as a contingency method has an operational time window dependant of both type of dispersant, oil properties and oil weathering, see Figure 1. The figure shows dispersant effectiveness (Corexit 9500) as a function of weathering (oil viscosity) for the MC252 oil released during the Macondo blowout [21]. For two test methods representing both high and low turbulence levels (MNS \& IFP) a reduction in dispersant effectiveness is observed as a function of weathering represented by viscosity of the emulsified oil. This highlights the significance of sea 

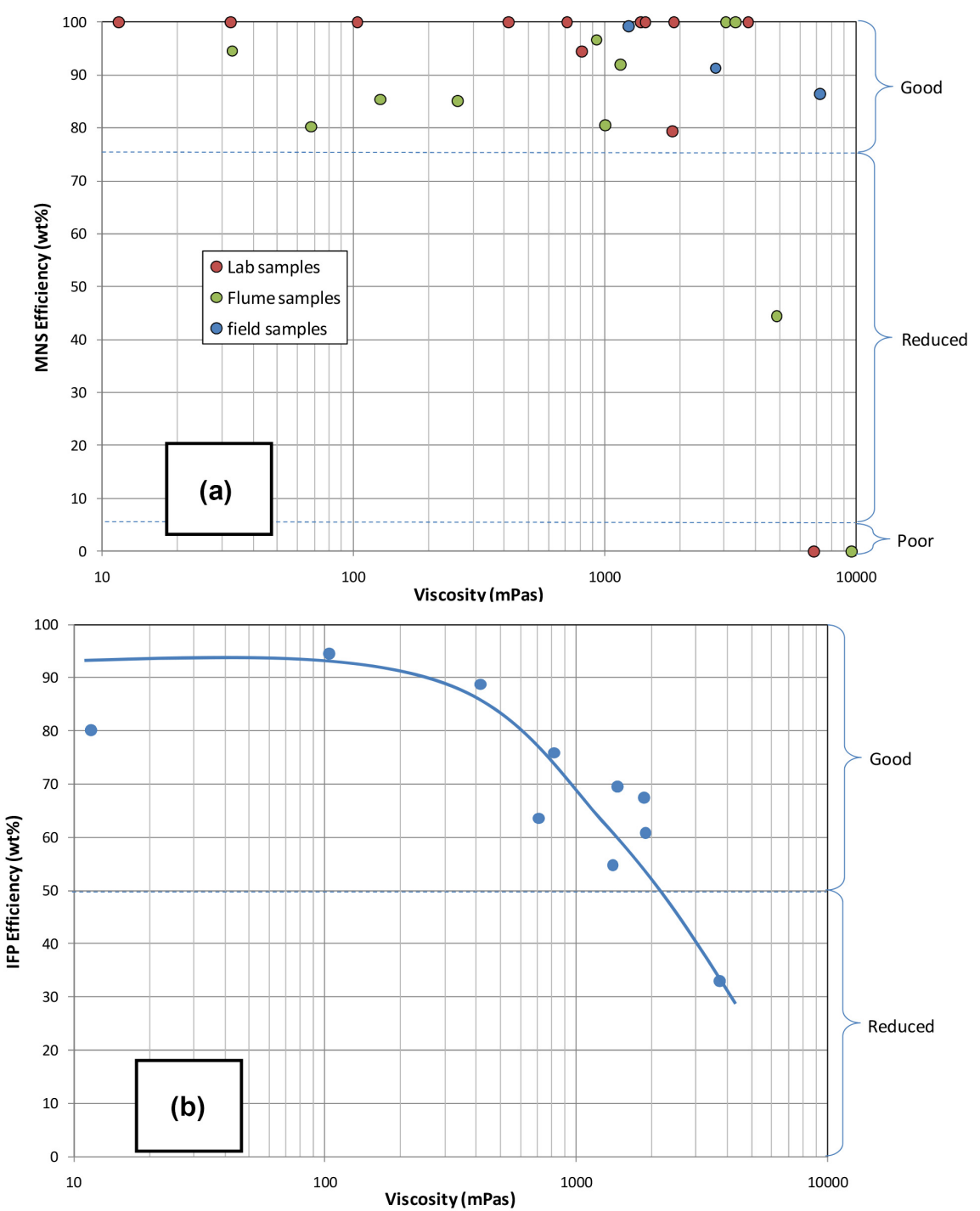

Figure 1. Dispersant effectiveness, (a): MNS (high turbulence) and (b): IFP (low turbulence) of weathered MC252 oil samples from laboratory, flume experiments and field-samples from the Gulf of Mexico (2010) is plotted against the viscosity for the samples, from [21].

state, since high effectiveness demands turbulence (breaking waves). Screening testing of dispersants for surface application could, for this reason, be done with artificially weathered oils and a relevant turbulence level (Figure 1) to estimate the time window for dispersant use on this oil type.

For subsea dispersant injection (SSDI), the situation is very different. The dispersant is applied directly into a stream of fresh warm oil usually under very turbulent conditions. Such conditions should be reflected and would probably demand other test protocol to offer dispersant ranking relevant for SSDI. The most significant factors for designing a new, and more relevant, bench-scale SSDI dispersant test could be:

1) The "Turbulence level" must reflect subsea release conditions and should be variable; 
2) The dispersant must be injected directly into the oil by a representative injection technique;

3) Effectiveness should be quantified as a reduction in oil droplet size;

4) It should be possible to relate release conditions in the test method to large-scale basin testing and real field conditions.

An effective test protocol should also include continuous monitoring of oil droplet sizes while dispersant is injected into a steady stream of oil, enabling efficient testing of a wide range of dispersant dosages of $0.1 \%$ to $4 \%$. This study presents results from a new test method that reflects turbulence levels, injection methods and quantification of effectiveness that are relevant for SSDI.

This approach called the Dispersant Injection Effectiveness Test (DIET) is a down-scaled version of a larger system used at SINTEF for multiple years, the Tower Basin [22]. This paper presents test results from a broad variety of oil types and dispersants and compares them to results from test systems designed for surface dispersant application (IFP and MNS). The results indicate a significant difference in product ranking between the different test methods. Oil companies operating in Norway have already for some years requested screening studies to rank possible dispersants for subsea injection and results from these studies are used as examples in this paper [23] [24] [25].

\section{Experimental}

The suggested concept for a new test method that reflects turbulence levels, dispersant injection and quantification of effectiveness relevant for SSDI is presented in Figure 2 and Figure 3.

Two different types of experiments were performed in this study: 1) Screening experiments as a function of dispersant type and dosage. 2) Experiments with varying oil temperature. The temperature experiments were performed to study the temperature influence on dispersant effectiveness and to identify a suitable oil temperature for the test protocol.

The conditions used under all the testing are:

Tank dimensions: $\quad 0.8 \mathrm{~m}, 0.5 \mathrm{~m}$ and $160 \mathrm{~L}$ (Height, Diameter, Volume);

Release diameter: $\quad 0.5 \mathrm{~mm}$ (circular);

Oil flow rate: $\quad 0.1 \mathrm{~L} / \mathrm{min}$;

Oil temperature range: $\quad 20^{\circ} \mathrm{C}$ to $80^{\circ} \mathrm{C}\left(20^{\circ} \mathrm{C}\right.$ for experiments with constant temperature);

Dispersant injection: $\quad$ Simulated injection tool (SIT);

Dispersant dosage: $\quad 0.1 \%-2 \%$;

Water flow-through rate: $30-100 \mathrm{~L} / \mathrm{min}$.

Prior to both test modes the MiniTower is thoroughly cleaned and flushed with filtered natural sea water filtered sea water (35 ppt) for 5 minutes (30 $1 / \mathrm{min})$. Separate programmable piston pumps are used for oil injection (1000 $\mathrm{ml}$ ) and for dispersant injection (100 $\mathrm{ml})$. The continuous flow of filtered natural sea water filtered sea water through the system was driven by the pressure for the 


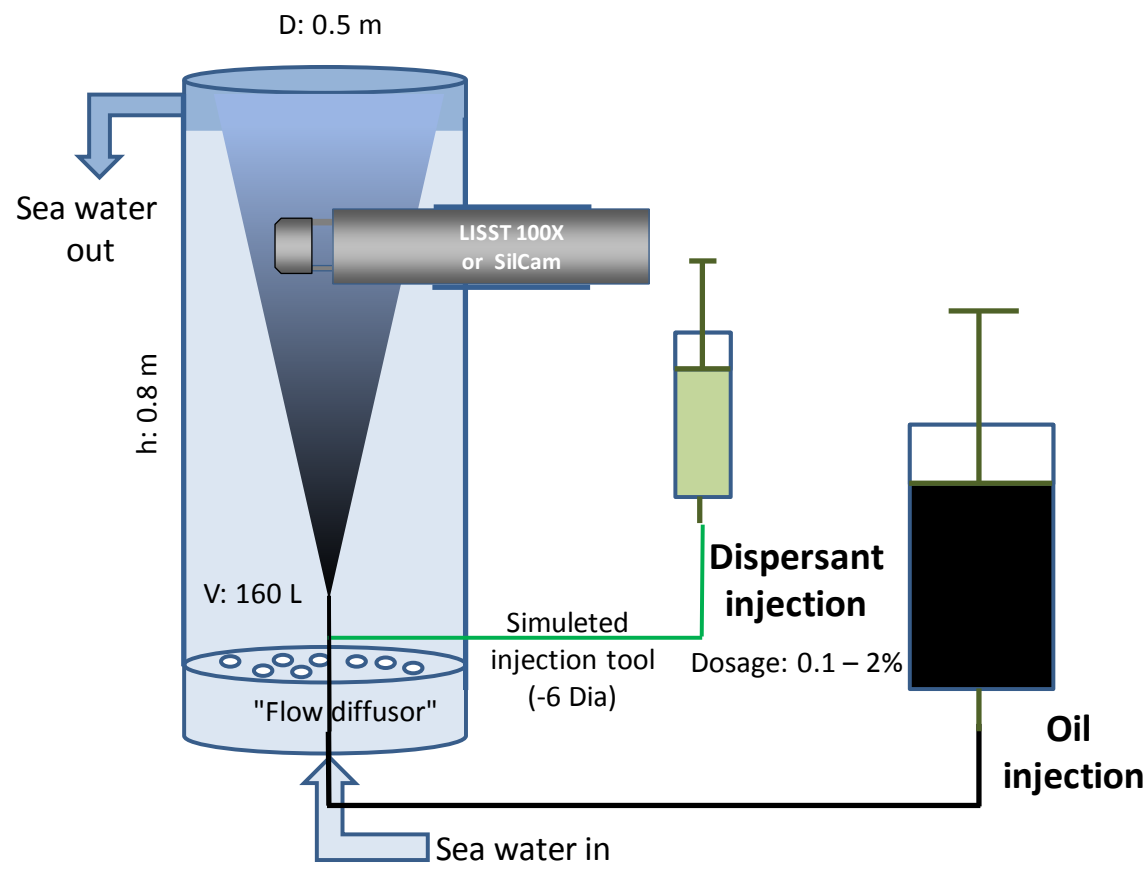

Figure 2. Outline of the new subsea Dispersant Injection Effectiveness Test (DIET), illustrating the flow-through system of natural sea water, injection system of dispersant and release system for oil. The LISST laser scattering system is used for monitoring droplet sizes.
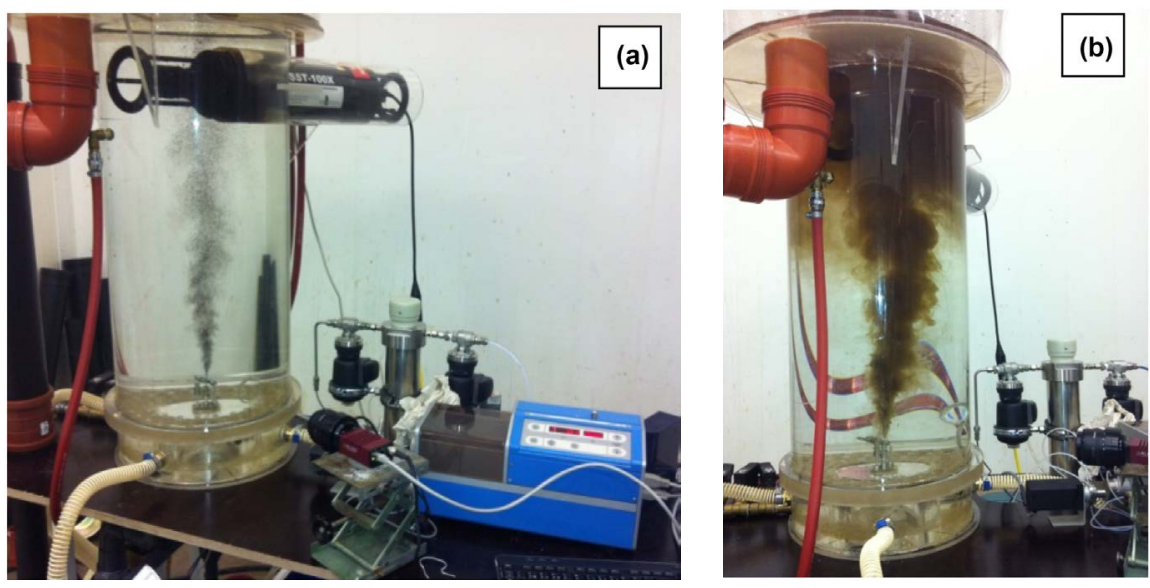

Figure 3. Continuous rising plume of untreated Oseberg blend (a) and oil treated with $1 \%$ dispersant (b). Dispersant injection syringe pump (blue box) is shown (a).

general sea water supply ( $6 \mathrm{~atm})$ used for all SINTEF Oceans's marine laboratories and can be regulated within $30-100 \mathrm{~L} / \mathrm{min}\left(9^{\circ} \mathrm{C}-12^{\circ} \mathrm{C}\right)$.

\subsection{Dosage Experiments}

The following procedure was used for these experiments:

1) The continuous flow of natural sea water was set to $30 \mathrm{~L} / \mathrm{min}$;

2) Background recording for 5 minutes with the LISST 100X or SilCam instrument; 
3) Untreated oil was injected, and droplet sizes were monitored for $60 \mathrm{sec}$ onds, see details in Section 2.2;

4) Dispersant was injected into the oil by simulated injection tool (SIT), see details in Section 2.4, and droplet sizes were monitored for 60 seconds;

$5)$ For each increase in dispersant dosage $(0.1 \%-2 \%)$ oil droplet sizes were monitored for 60 seconds;

6) The experiments were terminated with a replicate of untreated oil, see 3 above.

\subsection{Oil Temperature Experiments}

The general procedure described in the previous section was also used for these experiments, with the oil temperature as an additional parameter. Oil at ambient temperature $\left(20^{\circ} \mathrm{C}\right)$ was passed through a heat exchanger, heating the oil to $80^{\circ} \mathrm{C}$ with a rate of $6^{\circ} \mathrm{C} / \mathrm{min}$ for 10 minutes. Dispersant was injected (SIT) for $30 \mathrm{sec}$ onds at 60 seconds intervals during this period. This procedure gives droplet size data for the entire temperature range in intervals of approximately $10^{\circ} \mathrm{C}$ for both oil alone (untreated) and oil treated with dispersants. For a standardized test, the test should be performed at a standard temperature $\left(50^{\circ} \mathrm{C}\right)$. This elevated temperature is assumed to be more representative for subsea releases and will also minimize the challenges with viscous oils.

\subsection{Quantification of Oil Droplet Sizes}

The dispersant effectiveness in the prototype test apparatus is evaluated by the reduction in oil droplet sizes compared to untreated oil. The droplet size distribution is measured with a standard laser diffraction scattering instrument, LISST100X. The instrument was operated $50 \mathrm{~cm}$ above the nozzle to obtain stable, more homogenous conditions and to obtain necessary dilution of the oil plume (10 - 300 ppm).

Monodisperse spherical particles of 80 and $360 \mu \mathrm{m}$ were injected into the measuring path of the instrument for size calibration \& documentation.

Laser diffraction is largely unaffected by composition of particles since the scattering of laser light is observed at multiple, small forward angles. At these small angles, light scattering is determined almost entirely by light diffracted by the particle. Since the light transmitted through the particle makes only a weak contribution to the measured scattering, the method of laser diffraction is mostly independent of particle composition [26]. Thus, except for shape effects, laser diffraction offers an excellent method for size-distribution estimation. Uncertainties due to shape are small in these studies since the measured particles (oil droplets) are spherical [26] [27]. The optical density is dependent on concentration and droplet sizes and if it becomes too high it will reduce and obscure the light scattering. An optical path reducer (90\%) reducing the optical path from 50 $\mathrm{mm}$ to $5 \mathrm{~mm}$ was used to extend the concentration range for the LISST instrument. The instrument was also operated $50 \mathrm{~cm}$ above the release point to obtain a suitable dilution of the oil plume, while still giving sufficient optical density, 
producing a good signal to noise ratio in the diffraction patterns. The applied laser diffraction methods deliver an equivalent-sphere size distribution that is very suitable for the purpose of this study. The LISST instrument makes 10 measurements every second (covering 32 logarithmic spaced bins in the 5 - 500 $\mu \mathrm{m}$ range) and stores these as an average reading. An average over a 30 second period, which means 300 individual droplet size scans, was used in this study to quantify each droplet size distribution. Averaging over this period should reduce uncertainties resulting from variations in oil or dispersant flow rates and inhomogeneity in the rising oil \& gas plume. More details can be found elsewhere [28].

However, the LISST instrument cannot discriminate between oil droplets and gas bubbles and in cases were both oil \& gas were released a Silhouette Camera could be used to quantify both types of particles [29].

\subsection{Dispersant Injection Techniques}

The effectiveness of different dispersant injection techniques was evaluated in a separate study and one injection technique from this study was used in this work, Simulated insertion tool (SIT). With SIT, the dispersant is injected into the oil stream 6 nozzle diameters (D) before the release opening. The operational situation simulated by this injection technique could be dispersant being injected with a wand inserted 2.4 meters (6 D) down into a pipe with a diameter of $0.4 \mathrm{~m}$. Premixing of dispersant could lead to surfactant aggregate formation in the oil with long disintegration time ( $>100$ milliseconds) and hence reduce dispersant effectiveness due to rapid oil droplet formation ( $<10$ milliseconds). Premixed dispersants should for this reason not be used in laboratory experiments studying SSDI, further details are given in an earlier study [30].

\subsection{Selected Oil Types}

The four oil types used in this study were selected to span out oil properties (Table 1).

\subsection{Selected Dispersants}

The following dispersants were used in this study: Corexit 9500, Finasol OSR-52 and OSR-62, Super dispersant 25 and Dasic Slickgone NS. All dispersants were used as received from their suppliers.

\section{Results and Discussions}

Three different types of experiments are discussed in this section: 1) Dispersant dosage experiments, 2) Oil temperature experiments, and 3) Comparison of dispersant effectiveness screening for SSDI (DIET) and surface dispersant application (IFP).

\subsection{Dispersant Dosage Experiments}

Oil droplet distributions as a function of dispersant dosage using Corexit 9500 for four different oil types are presented in Figure 4(a)-(d). The figure presents 
Table 1. Properties of the oils used in this study.

\begin{tabular}{|c|c|c|c|c|c|}
\hline $\begin{array}{c}\text { Oil type } \\
\text { Name and ID number }\end{array}$ & $\begin{array}{l}\text { Density } \\
(\mathrm{g} / \mathrm{mL})\end{array}$ & $\begin{array}{l}\text { Pour point } \\
\quad\left({ }^{\circ} \mathrm{C}\right)\end{array}$ & $\begin{array}{c}\text { Wax content } \\
\text { (wgt.\%) }\end{array}$ & $\begin{array}{c}\text { Asphaltene } \\
\text { content } \\
\text { (wgt.\%) }\end{array}$ & $\begin{array}{c}\text { Viscosity } \\
\mathrm{mPa} \cdot \mathrm{s} \\
\left(100 \mathrm{~s}^{-1} / 13^{\circ} \mathrm{C}\right)\end{array}$ \\
\hline $\begin{array}{c}\text { Troll B } \\
\text { (ID: 2007-0287) } \\
\text { Naphthenic }\end{array}$ & 0.9001 & $<-36$ & 0.95 & 0.09 & 20 \\
\hline $\begin{array}{c}\text { Skrugard } \\
\text { (ID: 2011-0559) } \\
\text { Naphthenic }\end{array}$ & 0.8710 & $<-36$ & 1.9 & 0.05 & 32 \\
\hline $\begin{array}{c}\text { Brynhild } \\
\text { (ID: 2014-0336) } \\
\text { Asphaltenic }\end{array}$ & 0.8800 & -6 & 4.6 & 2.6 & 42 \\
\hline $\begin{array}{c}\text { Maria } \\
\text { (ID: 2012-0091) } \\
\text { Paraffinic }\end{array}$ & 0.8469 & -24 & 3.7 & 0.55 & 17 \\
\hline $\begin{array}{c}\text { Skarfjell } \\
\text { (ID: 2013-0595) } \\
\quad \text { Waxy }\end{array}$ & 0.8241 & -12 & 7.7 & 0.03 & 12 \\
\hline
\end{tabular}

droplet size distributions for untreated oil (black lines) compared to distributions as a function of increasing dispersant dosage $(0.1 \%-2 \%$ coloured lines). The SSDI effectiveness is interpreted as a shift in droplet size distributions towards smaller droplets compared to the untreated oil for (reduction in $\mathrm{d}_{50}$ ).

With the paraffinic Maria, the naphthenic Skrugard and the waxy Skarfjell (Figure 4(a)-(c)) the droplet size distributions for the untreated oils $\left(\mathrm{d}_{50}\right.$ : 318 $250 \mu \mathrm{m})$ are gradually shifted towards smaller droplets and results in distributions with a $\mathrm{d}_{50}$ of $48-62 \mu \mathrm{m}$ for the highest dosages (2\%).

A systematic shift in $\mathrm{d}_{50}$, when the dispersant dosage was increased, was also observed for the asphaltenic Brynhild (Figure 4(d)), but the distributions became broader when the dispersant dosages are increased. The distributions also showed a significant deviation from a lognormal distribution observed with the other oils. This broadening and skewness could be caused by an interaction between the surfactants in the dispersant and the naturally occurring surface active components in the asphaltenic Brynhild. These components are mainly polar material in the oil, like naphthenic acids, short chain alcohols, NSO-components and heavier polar material more abundant in such asphaltenic crudes.

A comparison of the quantified oil droplet distributions for the four dispersants (coloured lines) is presented in Figure 5 for one oil type (Maria) and one dosage (1\%). The untreated oil is given as a reference (black line). Three of the dispersants (Corexit 9500, Finasol 52 and Superdispersant 25) show similar effectiveness $\left(\mathrm{d}_{50}\right.$ : $\left.63-75 \mu \mathrm{m}\right)$ on this light paraffinic crude, while Dasic NS is less effective and generates significant larger oil droplets $\left(d_{50}: 128 \mu \mathrm{m}\right)$ at the same dosage.

\subsection{0il Temperature}

The main objective for this part of the work was to study SSDI effectiveness dependency of oil temperature and to find a suitable oil temperature for a 


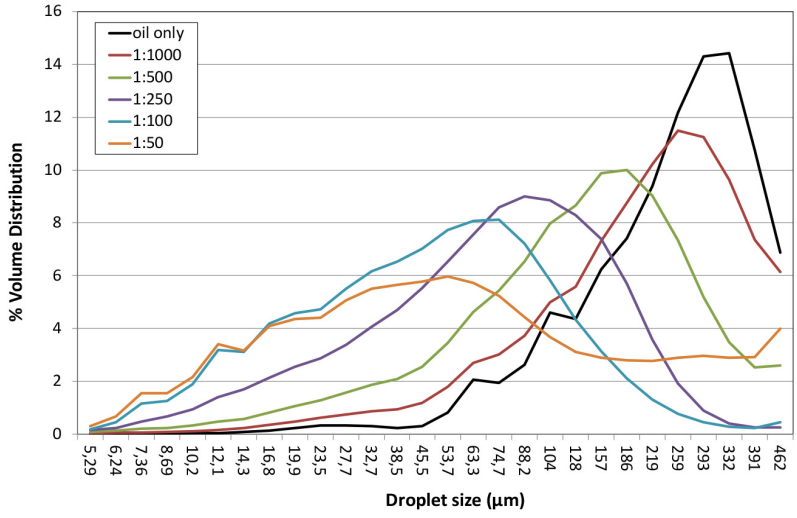

(a)

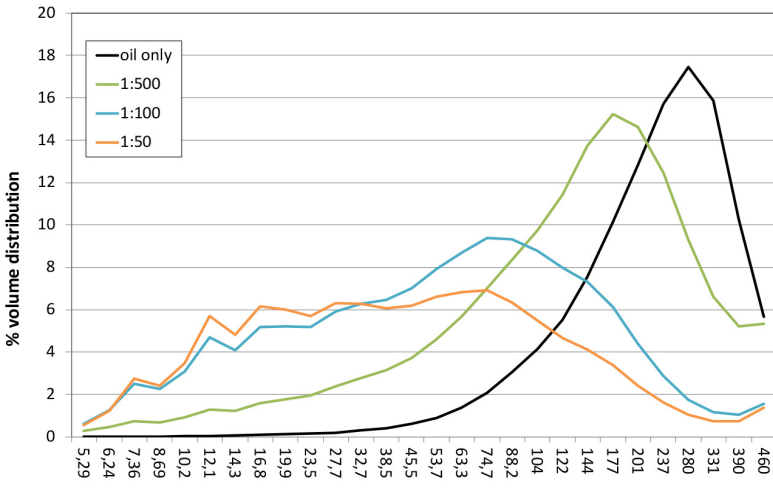

(b)

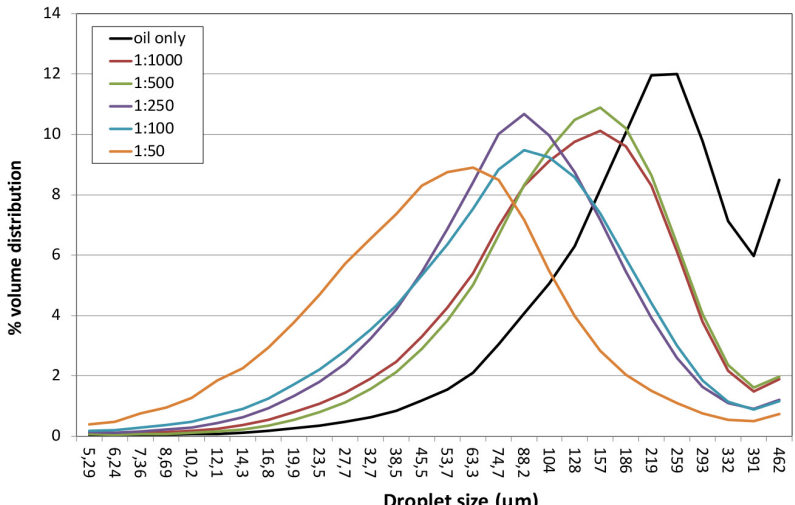

(c)

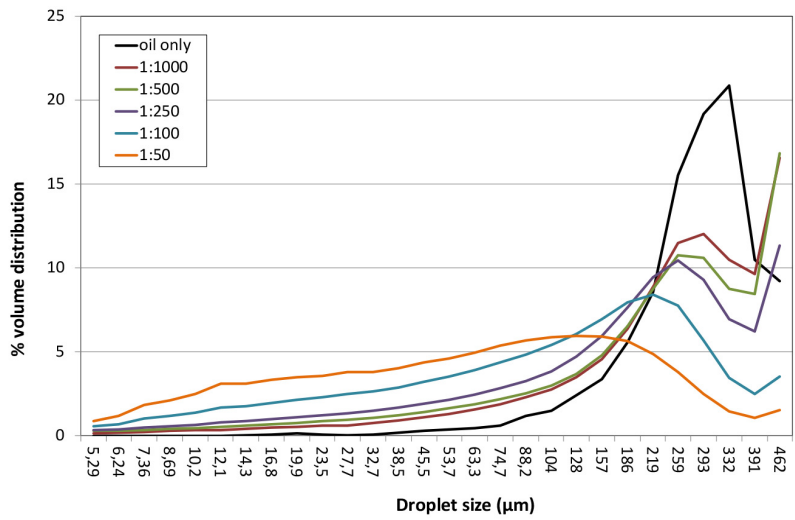

Figure 4. Droplet size distributions (volume \%) for oil alone and dispersant injection (Corexit 9500) as a function of dispersant dosage $(0.1 \%-2 \%)$ for (a): Maria (Paraffinic), (b): Skrugard (Napthenic), (c): Skarfjell (Waxy) and (d): Brynhild (Asphaltenic). 


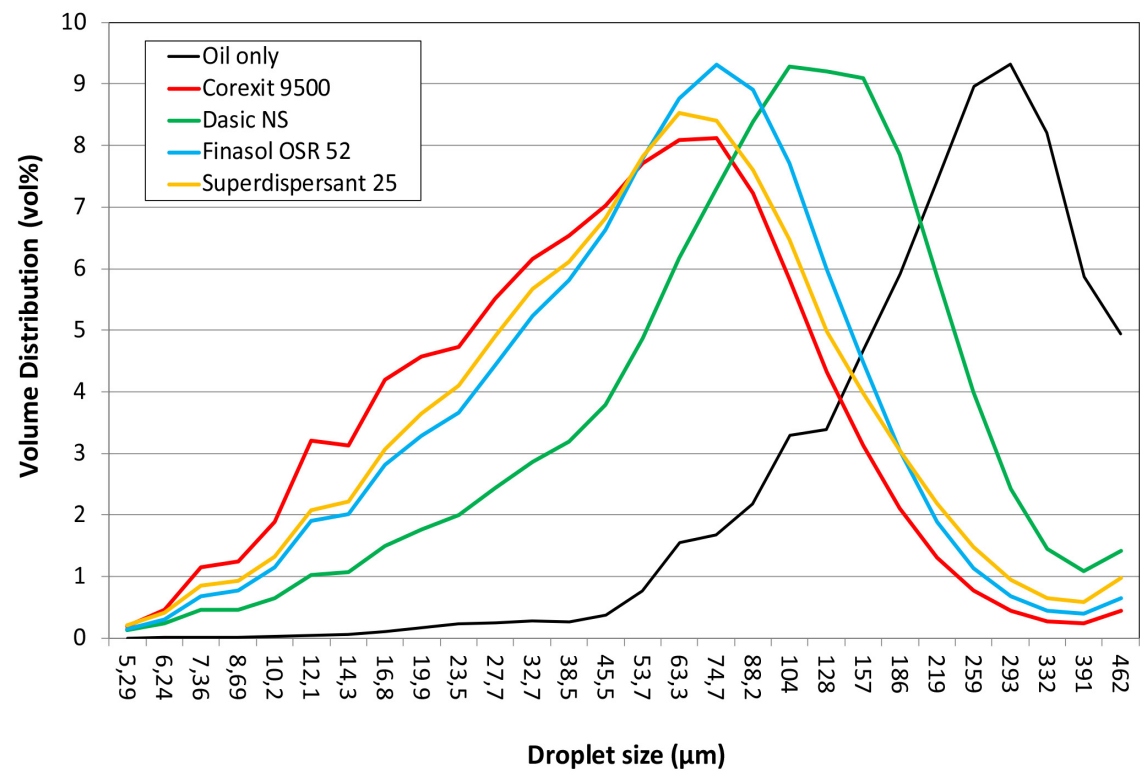

Figure 5. Summary figure presenting droplet size distributions for all four dispersants (Corexit 9500, Superdispersant 25, Finasol OSR-52 and Dasic NS) on the paraffinic Maria oil. Dispersant dosage is $1 \%$ with SIT injection.

standardised test. SSDI effectiveness expressed as $\mathrm{d}_{50}$ (1\% dispersant dosage) as a function of temperature $\left(20^{\circ} \mathrm{C}-80^{\circ} \mathrm{C}\right)$, is presented for Troll B and Brynhild oils Figure 6(a), Figure 6(b). The general trend with both oil types is that reduced oil viscosity (with increased temperature) results in smaller oil droplets. The increased effectiveness with oil temperature (smaller droplet) can be explained by a reduction in oil viscosity and oil-water interfacial tension (IFT). Molecular diffusion rates for the injected surfactants to the oil-water interface could also be higher at reduced viscosities.

As observed in the previous section, there are also significant differences in effectiveness between the four dispersants tested as a function of oil temperature. The SSDI effectiveness as a function of temperature shows that three of the dispersants (Finasol OSR-52, Corexit 9500 and Superdispersant 25) have similar effectiveness while the forth (Dasic NS) is generating significantly larger droplets (Figure 6(a), Figure 6(b)).

\subsection{Comparison of Dispersant Screening Results}

To compare screening results from existing methods for surface dispersant application (IFP) and results from the new bench-scale test for SSDI effectiveness (DIET), composite figures for two oil types were made. Dispersant effectiveness for both SSDI and surface dispersant application for the paraffinic Maria and the asphaltenic Brynhild are presented in Figure 7 and Figure 8. In Figure 7(a), Figure 7(b) results from OSR-52 are used together with results from OSR-62. This is not expected to introduce large uncertainties, since these two products show very similar effectiveness on this oil type [23]. 


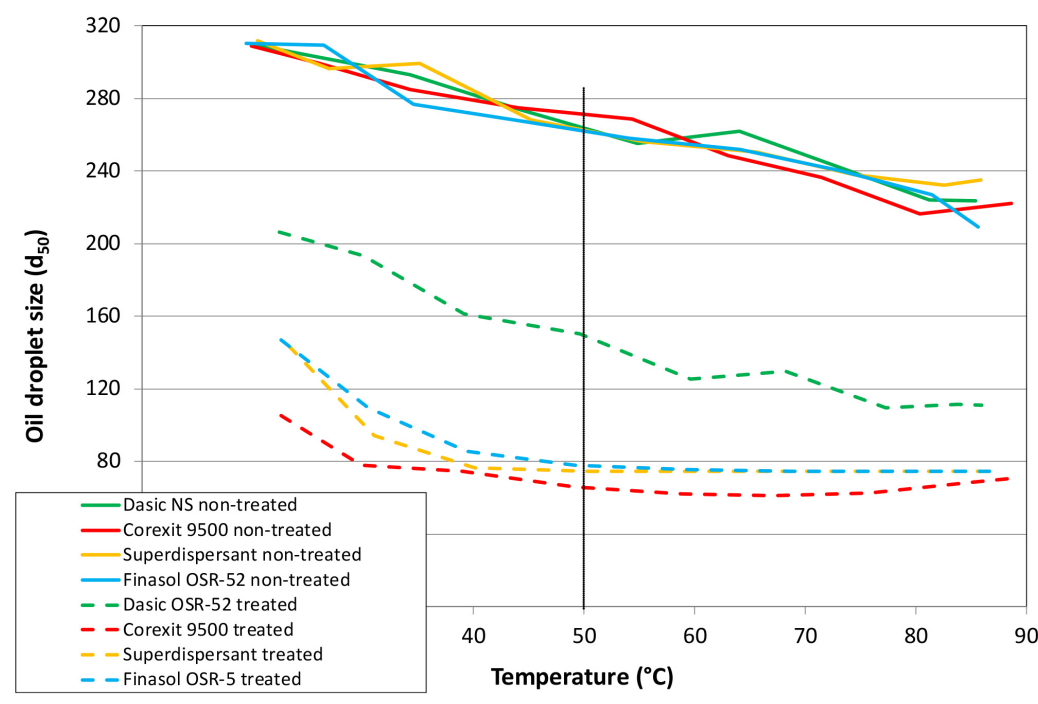

(a)

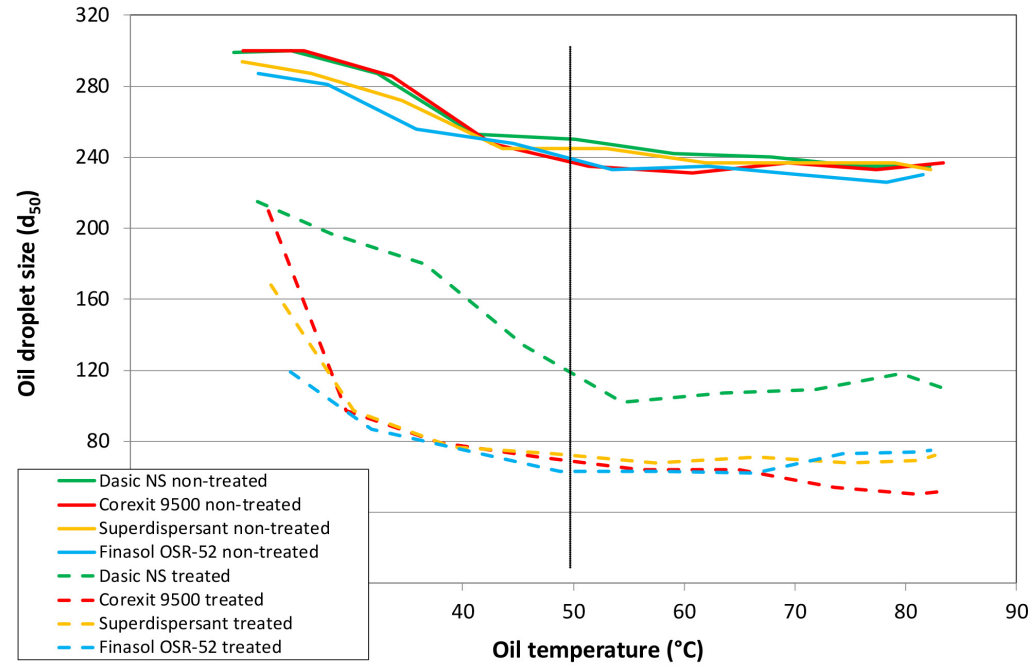

(b)

Figure 6. SSDI effectiveness with (a) Troll B (naphthenic) and (b) Brynhild (asphaltenic) as a function of oil temperature $\left(20^{\circ} \mathrm{C}-80^{\circ} \mathrm{C}\right)$ expressed as averaged droplet sizes $\left(\mathrm{d}_{50}\right)$ over a 15 seconds period. Lines illustrate $50^{\circ} \mathrm{C}$ selected for the standardised test conditions.
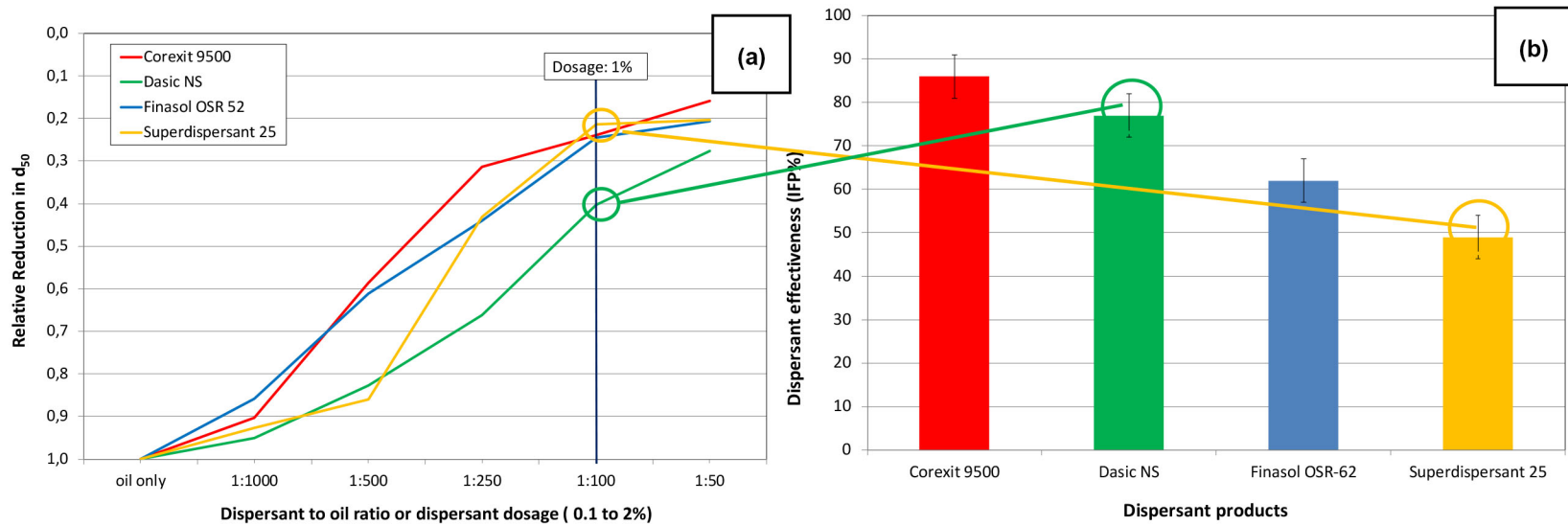

Figure 7. Comparison of dispersant ranking from screening testing. (a): Subsea injection (DIET, fresh oil, SIT injection), and (b): Standard dispersant testing for surface application (IFP, 50\% emulsion, $900 \mathrm{cP}$, dropwise application) with the Maria oil (paraffinic) [23]. Error bars are indicating \pm 1 std for the method (5\%). 

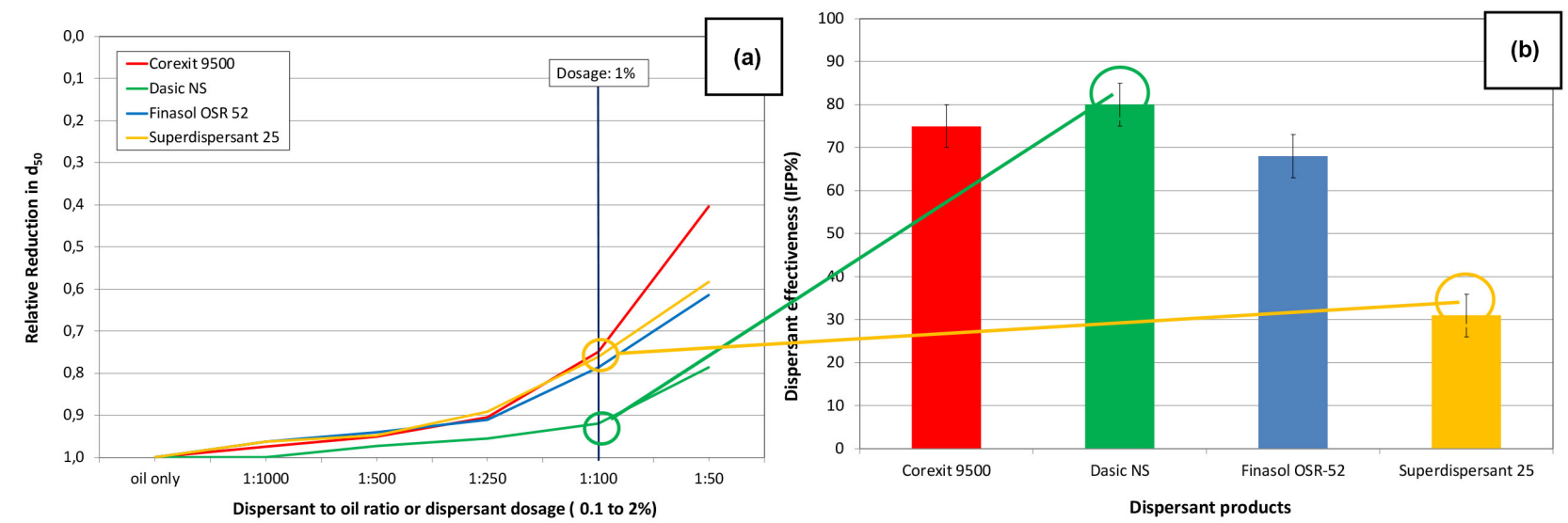

Figure 8. Comparison of dispersant ranking from screening testing. (a): Subsea injection (DIET, fresh oil, SIT injection), and (b): Standard dispersant testing for surface application (IFP, 50\% emulsion, $1830 \mathrm{cP}$, dropwise application) with the Brynhild oil (asphaltenic) [24]. Error bars are indicating \pm 1 std for the method (5\%).

The effectiveness of the two dispersant application methods are presented as:

1) DIET: Relative reduction in droplet size $\left(\mathrm{d}_{50}\right)$ as a function of dispersant type (line colour) and dosage ( $\mathrm{x}$-axis, $0.2 \%-2 \%)$. For example, a value of $0.3 \mathrm{in}$ dicates that droplet size $\left(\mathrm{d}_{50}\right)$ is reduced to $30 \%$ of the untreated oil;

2) IFP: Relative removal of oil from the surface $(0 \%-100 \%)$ in the test method (IFP) as a function of dispersant type (coloured bars).

This approach for presenting SSDI effectiveness offers a significant improvement over the direct comparison of oil droplet distributions presented in Figure 4 and Figure 5. It is easier to see from Figure 7(a) that Dasic NS (green line), with a $1 \%$ dosage, only reduces $d_{50}$ to $40 \%$, while the other dispersants reduce the droplet sizes to approximate $25 \%$ of the untreated oil droplets. We can also observe from the same figure, that Dasic NS generally gives a lower performance for this oil type and that Superdispersant 25 needs a dosage above $0.25 \%$ to be comparable with Corexit 9500 and Finasol OSR-52.

We can also clearly see that DIET shows reduced dispersant effectiveness with the asphaltenic Brynhild (Figure 8) compared to the paraffinic Maria. Even with an increased dosage (2\%) the reduction in droplet sizes are significantly lower, only $40 \%-60 \%$ of the untreated oil.

When comparing the A and B parts of Figure 7 and Figure 8 (DIET versus IFP), we observe that the ranking of the dispersants is significantly different. From the IFP testing, Dasic-NS is generally ranked high and Superdispersant 25 is ranked low, for all oil types. This is almost the opposite for DIET where Superdispersant 25 generally is ranked very high and Dasic NS is ranked low. The main differences and similarities between the dispersant effectiveness tests relevant for surface application and subsea dispersant injection are summarised in Table 2 below.

The turbulence in the DIET system is mainly determined by the nozzle exit velocity of the released oil and gas and might be upscaled to field conditions using the principles of Weber number scaling [31]. 
Table 2. Comparison of the most relevant properties for: 1) the two dispersant effectiveness tests used for surface application (IFP and MNS), and 2) for Subsea Dispersant Injection (DIET).

\begin{tabular}{|c|c|c|}
\hline & $\begin{array}{l}\text { 1: Surface Application } \\
\text { (IFP and MNS) }\end{array}$ & $\begin{array}{l}\text { 2: Subsea Dispersant Injection } \\
\text { (DIET) }\end{array}$ \\
\hline Dispersant Application & $\begin{array}{l}\text { Sprayed on } \\
\text { weathered/emulsified surface oil }\end{array}$ & $\begin{array}{l}\text { Injected into a stream of } \\
\text { fresh/warm oil }\end{array}$ \\
\hline Principle for Turbulence & Simulated surface waves & Highly turbulent jet (oil \& gas) \\
\hline Quantification of Effectiveness & $\begin{array}{l}\text { Percent of oil removed } \\
\text { from the surface }\end{array}$ & $\begin{array}{l}\text { Reduction in oil droplet } \\
\text { size }\left(\mathrm{d}_{50}\right)\end{array}$ \\
\hline
\end{tabular}

\section{Conclusions and Perspectives}

SSDI effectiveness as reduction of oil droplet sizes $\left(d_{50}\right)$ is presented for oil types spanning a large variety in oil properties, using four dispersants over a wide dosage range. This extensive screening study produce a ranking of the dispersants that vary with the different oil properties (oil types).

However, the most significant result is that the dispersant ranking obtained with the new test (DIET), is very different from screening results obtained from test methods for surface application of dispersants (IFP). This indicates that existing standard methods for dispersant effectiveness testing are less relevant for SSDI effectiveness testing and justifies the need for a more relevant method. Such a method is described and documented in this study. This is also in accordance with conclusions by Coolbaugh and Cox [32] based on a related study performed at Cedre \& SINTEF, which also included some of the data from this study.

The main features for the new test protocol are:

- Relevant turbulence regime for subsea releases of oil (turbulent jet);

- Dispersant effectiveness quantified by reduction in oil droplets sizes versus untreated oil;

- A sea water flow-through system enables a wide range of concentration and droplets sizes;

- Realistic and operationally relevant injection of dispersant directly into the oil;

- Relevant and elevated oil temperature $\left(50^{\circ} \mathrm{C}\right)$;

- Can easily be used over a wide range of dispersant dosage;

- Monitoring during continuous release of oil offering statistically significant results;

- Can easily be highly automated, quick and cost effective.

The main reason for the difference in dispersant ranking between the new protocol and existing protocols for surface dispersant application is probably that dispersing a weathered viscous emulsion is significantly more challenging compared to SSDI testing, where the dispersant is injected into fresh oil under highly turbulent conditions. 


\section{Acknowledgements}

The main part of this study has been funded by Statoil Petroleum AS (now Equinor) under contract 4503328838 and by IPIECA/OGP under contract 2013-8016-12-060.

\section{Conflicts of Interest}

The authors declare no conflicts of interest regarding the publication of this paper.

\section{References}

[1] Mackay, D. and Szeto, F. (1980) Effectiveness of Oil Spill Dispersants-Development of a Laboratory Method and Results for Selected Commercial Products. Institute of Env. Studies, University of Toronto, Toronto, Publ. No. EE-16.

[2] Martinelli, F.N. (1984) The Status of the Warren Spring Laboratory's Rolling Flask Test. In: Allen, T.E., Ed., Oil Spill Chemical Dispersants. Research, Experience and Recommendations, STP 840, American Society for Testing and Materials, Philadelphia, 55-68. https://doi.org/10.1520/STP30228S

[3] Bocard, C., Castaing, C.G. and Gatellier, C. (1984) Chemical Oil Dispersion in Trials at Sea and in Laboratory Tests: The Key Role of the Dilution Process. In: Allen, T.E., Ed., Oil Spill Chemical Dispersants. Research, Experience and Recommendations, ASTM STP 840, American Society for Testing and Materials, Philadelphia, 125-142. https://doi.org/10.1520/STP30233S

[4] Becker, K.W., Coker, L.G. and Walsh, M.A. (1991) A Method for Evaluating Oil-Spill Dispersants Exxon Dispersant Effectiveness Test (EXDET). OCEANS 91 Proceedings, Honolulu, 1-3 October 1991, 1486-1490.

[5] Venosa, A.D., King, D.W. and Sorial, G.A. (2002) The Baffled Flask Test for Dispersant Effectiveness: A Round Robin Evaluation of Reproducibility and Repeatability. Spill Science \& Technology Bulletin, 7, 299-308. https://doi.org/10.1016/S1353-2561(02)00072-5

[6] Sorial, G.A., Venosa, A.D., Miller, K.M., Holder, E.L. and King, D.W. (2004) Oil Spill Dispersant Effectiveness Protocol-Part I. Impact of Operational Variables. Journal of Environmental Engineering, 130, 1073-1084. https://doi.org/10.1061/(ASCE)0733-9372(2004)130:10(1073)

[7] Sorial, G.A., Venosa, A.D., Miller, K.M., Holder, E. and King, D.W. (2004) Oil Spill Dispersant Effectiveness Protocol. Part II. Performance of the Revised Protocol. Journal of Environmental Engineering Division, 130, 1085-1093. https://doi.org/10.1061/(ASCE)0733-9372(2004)130:10(1085)

[8] Kaku, V.J., Boufadel, M.C. and Venosa, A.D. (2006) Evaluation of Mixing Energy in Laboratory Flasks Used for Dispersant Effectiveness Testing. Journal of Environmental Engineering, 132, 93-101. https://doi.org/10.1061/(ASCE)0733-9372(2006)132:1(93)

[9] Zhao, L., Wang, B., Armenante, P., Conmy, R. and Boufadel, M. (2015) Characterization of Turbulent Properties in the EPA Baffled Flask for Dispersion Effectiveness Testing. Journal of Environmental Engineering, 142, Article ID: 04015044. https://doi.org/10.1061/(ASCE)EE.1943-7870.0001000

[10] Desmarquest, J.P., Croquette, J., Merlin, F., Bocard, C., Castaing, G. and Gatellier, C. (1985) Recent Advances in Dispersant Effectiveness Evaluation: Experimental 
and Field Aspects. International Oil Spill Conference Proceedings, Los Angeles, 25-28 February 1985, 445-452. https://doi.org/10.7901/2169-3358-1985-1-445

[11] Belore, R., Trudel, K., Mullin, V.J. and Guarino, A. (2009) Large-Scale Cold Water Dispersant Effectiveness Experiments with Alaskan Crude Oils and Corexit 9500 and 9527 Dispersants. Marine Pollution Bulletin, 58, 118-128.

https://doi.org/10.1016/j.marpolbul.2008.08.013

[12] Trudel, B.K., Belore, R.C., Lewis, A., Guarino, A. and Mullins, J. (2005) Determining the Viscosity Limits for Effective Chemical Dispersion: Relating Ohmsett Results to Those from Test At-Sea. In: International Oil Spill Conference, Miami Beach, Florida USA, May 2005, 71-76. https://doi.org/10.7901/2169-3358-2005-1-71

[13] Belore, R. (2015) Wave Tank Dispersant Effectiveness Tests on Alaskan Crude Oils. Proceedings of the 38th AMOP Technical Seminar, Ottawa, 2 June 2015, 687-702.

[14] Holder, E.L., Conmy, R.N. and Venosa, A.D. (2015) Comparative Laboratory-Scale Testing of Dispersant Effectiveness of 23 Crude Oils Using Four Different Testing Protocols. Journal of Environmental Protection, 6, 628-639. https://doi.org/10.4236/jep.2015.66057

[15] Lunel, T., Davies, L. and Brandvik, P.J. (1995) Field Trials to Determine Dispersant Effectiveness at Sea. Proceedings of the 18th AMOP Technical Seminar, Ottawa, 14-16 June 1995, 603-627. https://doi.org/10.7901/2169-3358-1995-1-147

[16] Lunel, T. and Wood, P.A. (1996) A Laboratory Dispersant Effectiveness Test Which Reflects Dispersant Efficiency in the Field. Proceedings of the 19th AMOP Technical Seminar, Ottawa, 461-480.

[17] Daling, P.S. and Lichtenthaler, R.G. (1986) Chemical Dispersion of Oil. Comparison of the Effectiveness Results Obtained in Laboratory and Small-Scale Field Tests. Oil \& Chemical Pollution, 3, 19-35. https://doi.org/10.1016/S0269-8579(86)80011-9

[18] Brandvik, P.J., Lunel, T., Daling, P.S. and Lewis, A. (1995) Measurements of Dispersed Oil Concentrations by In-Situ UV Fluorescence during the Norwegian Experimental Oil Spill 1994 with Sture Blend. Proceedings of the 18th AMOP Technical Seminar, Ottawa, 14-16 June 1995, 519-535.

[19] Faksness, L.-G., Brandvik, P.J., Daling, P.S., Singsaas, I. and Sørstrøm, S.E. (2016) The Value of Offshore Field Experiments in Oil Spill Technology Development for Norwegian Waters. Marine Pollution Bulletin, 111, 402-410.

https://doi.org/10.1016/j.marpolbul.2016.07.035

[20] Daling, P.S., Brandvik, P.J., Mackay, D. and Johansen, Ø. (1990) Characterisation of Crude Oils for Environmental Purposes. Oil and Chemical Pollution, 7, 199-224. https://doi.org/10.1016/S0269-8579(05)80027-9

[21] Daling, P.S., Leirvik, F., Reed, M., Almås, I.K., Brandvik, P.J., Hansen, B.H., Lewis, A. and Reed, M. (2014) Surface Weathering and Dispersibility of Macondo MC252 Crude Oil. Marine Pollution Bulletin, 87, 300-310. https://doi.org/10.1016/j.marpolbul.2014.07.005

[22] Brandvik, P.J., Johansen, Ø., Leirvik, F., Farooq, U. and Daling, P.S. (2013) Droplet Breakup in Sub-Surface Oil Releases-Part 1: Experimental Study of Droplet Breakup and Effectiveness of Dispersant Injection. Marine Pollution Bulletin, 73, 319-326. https://doi.org/10.1016/j.marpolbul.2013.05.020

[23] Andreassen, I., Johnsen, M. and Leirvik, F. (2013) Weathering Studies of Maria Crude Oil. SINTEF Report No. A24674 (Unrestricted), Trondheim, August 2015.

[24] Hellstrøm, K.C., Johnsen, M. and Krause, D.F. (2015) Brynhild Crude Oil-Properties and Behaviour at Sea. SINTEF Report No. A27135 (Unrestricted), Trondheim, Au- 
gust 2015.

[25] Øksenvåg, J.H.C. (2014) Skrugard Crude Oil-Weathering Studies. SINTEF Report No. A22589 (Unrestricted), Trondheim, March 2012.

[26] Andrews, S., Nover, D. and Schladow, S.G. (2010) Using Laser Diffraction Data to Obtain Accurate Particle Size Distributions: The Role of Particle Composition. Limnology \& Oceanography. Methods, 8, 507-526. https://doi.org/10.4319/lom.2010.8.507

[27] Karp-Boss, L., Azevedo, L. and Boss, E. (2007) LISST-100 Measurements of Phytoplankton Size Distribution: Evaluation of the Effects of Cell Shape. Limnology and Oceanography: Methods, 5, 396-406. https://doi.org/10.4319/lom.2007.5.396

[28] Davies, E.J., Nimmo-Smith, W.A.M., Agrawal, Y.C. and Souza, A.J. (2012) LISST-100 Response to Large Particles. Marine Geology, 307-310, 117-122. https://doi.org/10.1016/j.margeo.2012.03.006

[29] Davies, B. and Leirvik (2017) The Use of Spectral Transmittance Imaging to Size and Classify Suspended Particulate Matter in Seawater. Marine Pollution Bulletin, 115, 402-410. https://doi.org/10.1016/j.marpolbul.2016.11.063

[30] Brandvik, P.J., Johansen, Ø., Leirvik, F., Krause, D.F. and Daling, P.S. (2018) Subsea Dispersants Injection (SSDI), Effectiveness of Different Dispersant Injection Techniques-An Experimental Approach. Marine Pollution Bulletin, 139, 385-393. https://doi.org/10.1016/j.marpolbul.2018.09.021

[31] Johansen, Ø., Brandvik, P.J. and Farooq, U. (2013) Droplet Breakup in Sub-Surface Oil Releases-Part 2: Predictions of Droplet Size Distributions with and without Injection of Chemical Dispersants. Marine Pollution Bulletin, 73, 327-335. https://doi.org/10.1016/j.marpolbul.2013.04.012

[32] Coolbaugh, T. and Cox, R. (2015) Development of a Bench Scale Effectiveness Test for Subsea Dispersant Use: An Oil Spill Response Joint Industry Project of the International Association of Oil and Gas Producers and IPIECA. Proceedings of the 38th AMOP Technical Seminar, Environment Canada, Ottawa, 703-714. 